\title{
Nourishing Life - Chinese Environmental Wisdom and Practices
}

\author{
Alicja Dłużewicz \\ (Adam Mickiewicz University in Poznań; alicja.dluzewicz@gmail.com) \\ ORCID: 0000-0002-4208-4535
}

\begin{abstract}
Increasingly recognized threats from climate change and the progressive sixth mass extinction require not only searching for new technological solutions, but also changing the perception of the world and the beings living in it. There is an urgent need to include individual practices; practices that are an integral part of integrated policies to protect habitats, the climate, and the homo sapiens itself. Eric S. Nelson, in his latest book Daoism and Environmental Philosophy. Nourishing Life introduces the reader to the environmental approach known to Chinese communities for centuries. In a comprehensive and accurate manner, the author presents the Chinese approach to life and development, the understanding and interpretation of which has changed over the centuries, invariably emphasizing man's belonging to the world of nature. This review introduces the author's assumptions presented in the book, combining them with relatively new thoughts and paradigms appearing in the 20th and 21st centuries in Western Europe and the United States.
\end{abstract}

Keywords: Eric S. Nelson; Daoism; Chinese Philosophy; the natural rhythm of life; nourishing life; environmental philosophy; holistic approach.

This is a review of the new book by Eric S. Nelson, Daoism and Environmental Philosophy. Nourishing Life, Routledge, New York (2020) ${ }^{1}$. Eric S. Nelson is a professor of philosophy at the Hong Kong University of Science and Technology, and his research interests are focused on Critical Social Theory, Hermeneutics, Phenomenology, Daoist and Buddhist Philosophy, and Philosophy of Nature. He is a recognized researcher, known primarily for his works exploring the philosophy of religion, in particular Chinese beliefs. In Poland, he is better known as the author of works dealing with the subject of the philosophy of the $19^{\text {th }}$ and $20^{\text {th }}$ century, mainly A. Schopenhauer and M. Heidegger. Nelson's book convincingly shows how Chinese environmental wisdom can help humanity cope with the climate crisis in a sustainable way. The basis of the discussed solutions is development in accordance with the natural rhythm of life, its nourishing potential, and the awareness of sharing the world with other creatures undergoing the same changes. These insights, relatively new to developing capitalistic countries, constitute the most important core of the historical identity of subjects professing the principle of the Dao, which is both a path and a promise of a good life. 
The climate crisis and the sixth mass extinction we are witnessing require both developed and developing societies to look for solutions that will help not only our species survive, but also serve as a protective shield for other creatures with whom we share the planet. The challenge for humankind, namely that of meeting the goals set for the protection of the climate and living organisms, is associated with the need to develop multi-level and multi-dimensional solutions. As environmental sensitivity shows, limiting the ambition to save the world and careful prioritization make the most important political players too withdrawn and unprepared to take radical action. Focusing attention only on the economic constraints generated by the capitalist system alone deprives the decision-making units of a broad perspective. At the same time, we are losing sight of the true cost of the changes that are taking place - the death of next species and making life impossible in at least some parts of the world. Additionally, the withdrawn attitude and reluctance to introduce radical changes shifts environmental responsibility onto individuals. This not only reduces political activities to solving one specific environmental issue. Such an approach, although important for solving currently pressing problems, focuses on the search for contingent and provisional (socially, culturally, historically, etc. relative) solutions ${ }^{2}$ that remain a systematic action resonating with a number of other actions and responses from human actors. Specialization in the field of science, as well as the narrowing of research fields, results in an ever deeper, but in fact also more limited type of cognition, leaving behind the complexity of many phenomena that pose a real threat to various forms of life (Otto 2020).

Western philosophy, as well as the cognitive tools developed within it, repeatedly imposed a number of restrictions related to the ways of thinking about the natural world and other forms of life. In their narratives, philosophers and scientists very often drew a thick line between people and other life forms, as well as natural phenomena, making representatives of the homo sapiens species a pearl in the crown of creation. This heritage is at the same time a rich source for further concepts, as well as a burden that must be faced in the framework of humanistic discourses (Braidotti 2019) and the structures of thinking that constitute the perception of phenomena in the natural and life sciences.

The answer to the ongoing climate crisis, the disintegration of social bonds, also to empathy and mutual understanding, and the disappearance of many, even undiscovered species, may be the Daoist philosophy which Eric S. Nelson presents in his recent book Daoism and Environmental Philosophy Nourishing Life, in the context of possible environmental changes. The author presents a series of phenomena that intertwine with, or even interdepend on each other, creating a landscape of beliefs and practices, both social and related to self-forming, as well as to the world around people, as a mirage of religion, philosophy, and what, following Foucault, can be called techniques

2 The term contingency is borrowed form Richard Rorty's works and it is used as a term denoting the following meanings: individual approach, variety, randomness, inability to create and accept one, universal solution (also Habermas 1994). 
of self (Foucault 2014). It should be emphasized that the multitude of interpretations of the concepts themselves, as well as the coexistence of contradictory attitudes contained in the writings and teachings of various schools, make the phenomena discussed in the book even more interesting, and at the same time a reliable and comprehensive way to present the complexity of Chinese philosophy and the policies of subject-making.

The perspective presented by Nelson brings back such concepts as emptiness, peace, completeness and complementation, showing the shifting of meanings from the perspective known in Western philosophy towards a broader understanding offered by Daoist views. Focusing on a broad environmental perspective, presenting the sources and changes taking place in the world, which are reflected in human life and constituting existence, using examples relating to rivers, animals and further - the circulation of matter in a world full of diverse and yet identical beings - helps to understand not only the meaning of life and death as phenomena that are part of the fullness, but also the interdependence of different lives. This is what links Nelson's approach with the perspective proposed by Donna Haraway, which he invoked in the introduction (Nelson 2020, 6).

As Haraway repeatedly stresses in one of her most important works: "To be one is always to become with many" (Haraway 2008, 4), raising the issue of coexistence with other non-human beings. Both humans and non-human actors are part of one organism that undergoes the same micro and macro processes of dying and re-becoming, aging and rebirth. The human body is not only multi-layered, but also ambiguous, and is a life platform for many radically different creatures that live thanks to human organisms, while allowing them to function. The understanding of the points raised by Haraway and Lynn Margulis is actually a return to a different and much earlier articulated knowledge.

In the context of reflecting on and constructing practices and policies related to animal protection (and the protection animals' vital interests), the concept of nourishing life referred to by Nelson is one of the most important issues raised in this work. Understood in many ways, as a concept promoting growth, longevity, health and a subject-oriented 'art of being transformed into a higher embodiment of biospiritual being and the art of nourishing the life of others and the world as is evident' (Nelson 2020,1112), it opens up human subjectivity, incorporating an understanding of natural biological changes and an understanding of other non-human life forms. Chinese teachings place accents differently and are restored to culture in different times and forms. Nelson cites two particularly important positions with regard to nourishing life - strengthening one's own body and life through forms of growth and techniques of oneself (both on the spiritual and bodily level), as well as an approach that defines growth as caring for what is around, understanding the human being's place in a world that is infinitely full of other life forms. As the author emphasizes:

The Daoist emphasis on nurturing the common elemental body of life as well as one's own bodily being and cultivating an attentive receptive recognition of things 
and the intersecting patterns of life in their own ways of occurring help form the potential for an ethos and praxis that motivates a double therapeutics of self and society that encompasses both individual ecological thinking and behavior as well as systematic social-political policies and practices (Nelson 2020, 73).

The path of the Dao allows one to identify and recognize other beings, control one's development and growth, understood in terms of resource use and colonization of common spaces. This opens the possibility of harmonious coexistence with representatives of other species, questioning the hegemony of man promoted by anthropocentric discourses and returning to the river, cosmos and other animals which lead by example. Establishing oneself in the world and going beyond the selfish perception of one's own body and development will allow to construct embodied, responsible and environmentally oriented practices that will include the non-human animal and recognize it in its spiritual and material form, allowing all forms of life on the planet to flourish.

Eric S. Nelson's book is an original and stimulating proposition, thanks to which readers, and in particular activists involved in the fight for climate protection. They can get acquainted with ideas close to them that have been present in another culture for centuries. Chinese teachings, linking religion, philosophy and the art of living in harmony with the surrounding world, seem hard or even impossible for Western societies, especially since they require giving up hierarchical social structures. Perhaps, as Nelson suggests, going beyond the graded social framework would help in finding peace, understanding and empathy for beings who now have to experience human cruelty in many ways.

\section{References}

Braidotti R. 2019. Posthuman Knowledge. Cambridge: Polity Press.

Foucault M. 2014. Wrong-Doing, Truth-Telling. The Function of Avowal in Justice. Chicago

- London: The University of Chicago Press.

Habermas J. 1992. "The Unity of Reason in the Diversity of Its Voices," in J. Habermas

(Ed.), Postmetaphysical Thinking. Political Essays (pp. 115-148), Cambridge, Mass.: The MIT Press.

Haraway D. 2008. When Species Meet. Minneapolis - London: University of Minnesota Press.

Nelson E. S. 2020. Daoism and Environmental Philosophy. Nourishing Life. New York: Routledge.

Otto F. 2020. Angry Weather. Heat Waves, Floods, Storms, and the New Science of Climate Change. Vancouver - Berkeley: Greystone Books.

Margulis L. 2008. Symbiotic Planet. A New Look at Evolution. New York: Basic Books. 